\title{
The association of a reduced susceptibility to moxifloxacin in causative Clostridium (Clostridioides) difficile strain with the clinical outcome of patients
}

Marcela Krutova ${ }^{1 *}$, Vaclav Capek², Elka Nycova ${ }^{3}$, Sabina Vojackova ${ }^{4}$, Magda Balejova ${ }^{5}$, Lenka Geigerova ${ }^{6}$, Renata Tejkalova ${ }^{7}$, Lenka Havlinova ${ }^{8}$, Iva Vagnerova ${ }^{9}$, Pavel Cermak ${ }^{10}$, Lenka Ryskova ${ }^{11}$, Petr Jezek ${ }^{12}$,

Dana Zamazalova ${ }^{13}$, Denisa Vesela ${ }^{14}$, Alice Kucharova ${ }^{15}$, Dana Nemcova ${ }^{16}$, Martina Curdova ${ }^{17}$, Otakar Nyc ${ }^{1}$ and Pavel Drevinek ${ }^{1}$

\begin{abstract}
Objectives: To investigate the relationship between Clostridium (Clostridioides) difficile strain characteristics and C. difficile infection (CDI) outcome.

Methods: Between October and December 2017, 16 hospitals collected epidemiological data according to the European Centre for Disease Prevention and Control (ECDC) surveillance protocol for CDI. C. difficile isolates were characterized by ribotyping, toxin genes detection and antibiotic susceptibility testing to metronidazole, vancomycin and moxifloxacin.
\end{abstract}

Results: The overall mean CDI incidence density was 4.5 [95\% Cl 3.6-5.3] cases per 10,000 patient-days. From the 433 CDI cases, 330 (76.2\%) were healthcare-associated, 52 (12.0\%) cases were community-associated or of unknown origin and 51 (11.8\%) CDI cases recurrent; a complicated course of CDI was reported in 65 cases (15.0\%). Eighty-eight (20.3\%) of patients died and 59 of them within 30 days after the CDI diagnosis.

From the 379 C. difficile isolates, the most prevalent PCR ribotypes were $001(n=127,33.5 \%)$ and $176(n=44,11.6 \%)$. A total of $186(49.1 \%)$ isolates showed a reduced susceptibility to moxifloxacin (> $4 \mathrm{mg} / \mathrm{L})$ and $96.4 \%$ of them had Thr82lle in the GyrA. Nineteen isolates revealed reduced susceptibility to metronidazole and two isolates to vancomycin ( $>2 \mathrm{mg} / \mathrm{L}$ ). A fatal outcome was associated with a reduced susceptibility to moxifloxacin, the advanced age of the patients and a complicated course of CDI $(p<0.05)$. No association between ribotype, binary toxin and a reduced susceptibility to moxifloxacin and complicated course or recurrent CDI was found.

Conclusions: A reduced susceptibility to moxifloxacin, in causative C. difficile strains was associated with fatal outcome of the patients, therefore it is an important marker in surveillance of CDI.

Keywords: Clostridium difficile infection, Clostridioides difficile infection, Czech Republic, PCR ribotype 001, PCR ribotype 176, Moxifloxacin, Mortality

\footnotetext{
* Correspondence: marcela.krutova@lfmotol.cuni.cz

'Department of Medical Microbiology, Charles University, 2nd Faculty of

Medicine and Motol University Hospital, Prague, Czech Republic

Full list of author information is available at the end of the article
}

C C The Author(s). 2020 Open Access This article is licensed under a Creative Commons Attribution 4.0 International License, which permits use, sharing, adaptation, distribution and reproduction in any medium or format, as long as you give appropriate credit to the original author(s) and the source, provide a link to the Creative Commons licence, and indicate if changes were made. The images or other third party material in this article are included in the article's Creative Commons licence, unless indicated otherwise in a credit line to the material. If material is not included in the article's Creative Commons licence and your intended use is not permitted by statutory regulation or exceeds the permitted use, you will need to obtain permission directly from the copyright holder. To view a copy of this licence, visit http://creativecommons.org/licenses/by/4.0/ The Creative Commons Public Domain Dedication waiver (http://creativecommons.org/publicdomain/zero/1.0/) applies to the data made available in this article, unless otherwise stated in a credit line to the data. 


\section{Introduction}

Clostridium difficile, recently reclassified as Clostridioides difficile [1], is a leading pathogen of gastrointestinal infections in hospitalised patients [2]. Between 2005 and 2013, several European multicentre studies aimed at mapping $C$. difficile epidemiology in Europe and an increase of CDI incidence density was found to be concomitant with changes in prevailing ribotypes; however, the design of the studies varied [3].

To standardize CDI epidemiology data collection, the European centre for disease prevention and control (ECDC) released a surveillance protocol with three options of CDI surveillance intensity ("minimal, light and enhanced"). The "minimal option" collects hospital-level CDI data, the "light version" collects also CDI case-based data, including data on mortality. The "enhanced" option collects hospital data, CDI case based data and microbiological data. Microbiological data includes results on $C$. difficile isolates ribotyping, the presence of toxins $\mathrm{A} / \mathrm{B}$ or toxin genes and antimicrobial susceptibility testing to metronidazole, vancomycin and moxifloxacin [3]. While metronidazole and vancomycin are recommended as CDI treatment drugs [4], a reduced susceptibility to moxifloxacin a fluoroquinolone class of drug, is suggested as an epidemiological marker for certain $C$. difficile ribotypes spread in healthcare settings [5].

After a successful pilot testing of all three CDI surveillance levels in 2013 [6], 20 countries participated in the first European standardized CDI surveillance wave in 2016 [7]. The "enhanced" version of the CDI surveillance protocol was used in $44.0 \%(n=261)$ of all hospital surveillance periods $(n=593)$ but almost half of these data (118 periods) came from one country, Belgium. Moreover, characteristics of $C$. difficile isolates were not available for all enhanced case based data [7].

Therefore, we aimed to collect complete CDI surveillance data according to the "enhanced level" of ECDC surveillance protocol for CDI and to investigate the relationship between $C$. difficile strain characteristics and CDI outcome.

\section{Material and methods}

\section{Study protocol}

Between October and December 2017, 16 hospitals submitted epidemiological data on CDI patients, according to the ECDC surveillance protocol v 2.3 [8], and sent $C$. difficile isolates for further characterisation. Eight hospitals are tertiary care institutions, seven secondary care facilities and one hospital is a specialised organ transplant centre. The surveillance period covered a total of 16,109 hospital-beds, which was $20.1 \%$ of the hospitalbed capacity in the Czech Republic in 2017 [9].

The unformed stool sample of patients suspected of having CDI were tested at microbiological departments of participating hospitals based on a physician's request. All but one of the participating hospitals used a sensitive screening test, glutamate dehydrogenase, followed by the detection of toxins A/B. Of those, ten hospitals used the nucleic acid amplification test (NAAT) or a toxigenic culture for further investigation of GDH positive and toxins $\mathrm{A} / \mathrm{B}$ negative stool samples, while five hospitals, performed a $C$. difficile culture of GDH positive and toxin $\mathrm{A} / \mathrm{B}$ negative samples but did not confirm the presence of toxin genes or toxins $\mathrm{A} / \mathrm{B}$ in those $C$. difficile cultures. One hospital used a nucleic acid amplification test as a stand-alone test, which is not currently recommended [10].

\section{Clostridium difficile culture and isolates characterisation}

In $C$. difficile isolates, a capillary-electrophoresis ribotyping was performed according to the consensus protocol [11]. The presence of toxin genes $(t c d A$-toxin $A, t c d B$ toxin $\mathrm{B}, c t d A$ and $c d t B$ - binary toxin) was investigated by multiplex PCR [12]. The antibiotic susceptibility of the isolates to metronidazole, vancomycin and moxifloxacin was determined by the agar dilution method on Wilkins-Chalgren agar (Oxoid). The epidemiological cut-off values (ECOFFs) for metronidazole $(2 \mathrm{mg} / \mathrm{L})$, vancomycin $(2 \mathrm{mg} / \mathrm{L})$ and moxifloxacin $(4 \mathrm{mg} / \mathrm{L})$ were applied according to the European Committee on Antimicrobial Susceptibility Testing (EUCAST). The quinolone resistance-determining region (QRDR) in the $\operatorname{gyr} A$ gene was amplified and sequenced to investigate the molecular mechanism of reduced susceptibility to moxifloxacin [13], Supplementary data.

\section{Statistical analysis}

Differences between groups were evaluated using $\mathrm{x} 2$ test or Fisher exact test for categorical variables and the Wilcoxon test for continuous variables. A univariate logistic regression model was used for the analyses of associations between individual variables and outcomes of interest. Pvalues were adjusted for multiple comparisons using a Holm-Bonferroni method. A $p$-value of $\leq 0.05$ was considered statistically significant. Analyses were conducted using the R statistical software version 3.5.1 [14].

The mean CDI incidence density was calculated from the CDI incidence densities of each participating hospital. The patient's outcome was followed until the patient was discharged from hospital or died. There was no post-discharge follow up regarding the readmission or death of patients.

\section{Results}

\section{Clostridium Clostridioides difficile infections}

During the three-month surveillance period, 433 CDI cases were recorded in 16 hospitals. The average age of patients was 69.1 years (median 74 years) and $52 \%$ were 
females. The mean testing frequency was 54.0 [95\% CI 44.8-63.2] tests per 10,000 patient days. The mean CDI incidence density was 4.5 [95\% CI 3.6-5.3] cases per 10, 000 patient-days. Of 433 reported CDI cases, 330 (76.2\%) were healthcare associated, the incidence density 3.5 [95\% CI 2.8-4.1] cases per 10,000 patients-days. The origin of CDI at the same hospital was reported in 319 cases and at another hospital in 11 cases. Thirty-six cases (8.3\%) were community-associated and in 16 cases (3.7\%) the origin of CDI was unknown; the common-incidence density was 0.5 [95\% CI $0.3-0.8]$ cases per 10,000 patients-days. Fiftyone CDIs $(11.8 \%)$ were recurrent, with an incidence density of 0.5 [ $95 \%$ CI $0.3-0.7$ ] cases per 10,000 patients-days.

A complicated course of CDI (admission for CDI from the community; admission to an intensive care unit; surgery for toxic megacolon or death) was reported in 65 cases (15.0\%). Eighty-eight patients (20.3\%) died and of those, 28 patients had a complicated course of CDI ( $p=$ $0.00)$. Fifty-nine patients died within 30 days after CDI diagnosis and of those, 21 patients had a complicated course of CDI $(p=0.00)$.

Data on CDI by origin, course and outcome are summarised in Table 1.

\section{Microbiological data}

Of the 433 CDI cases, 379 C. difficile isolates $(87.5 \%$ of CDI cases) were available for further characterisation.
The most frequently found ribotypes were $001(n=127$, $33.5 \%$, detected in $16 / 16$ hospitals $)$ and $176(n=44$, $11.6 \%, 11 / 16$ hospitals). The remaining 208 isolates (54.9\%) belonged to 30 different ribotyping profiles. The prevalence of $5 \%$ was exceeded only by RTs: $014(n=24$; $6.3 \%)$ and $012(n=23 ; 6.1 \%)$.

All the $379 C$. difficile isolates carried the $t c d A$ gene (toxin A), and 378 isolates also carried the $t c d B$ (toxin B); one $C$. difficile isolate of the ribotype 033 was $t c d B$ gene negative. Seventy-five $(19.8 \%)$ of the $C$. difficile isolates (RTs: 023, 027, 033, 078, 126, 176 and two unrecognized profiles) also harboured the binary toxin genes ( $c d t A$ and $c t d B)$.

A reduced susceptibility to metronidazole was observed in 19 isolates (RTs: $001 n=8,027 n=6,176 n=$ 5 , the minimum inhibitory concentrations (MICs) were (3-8 $\mathrm{mg} / \mathrm{L})$ and an elevated MIC, reaching the breakpoint of $2 \mathrm{mg} / \mathrm{L}$, was observed in $47 \mathrm{C}$. difficile isolates (RT176 $n=16$; RT001 $n=25$; RT027 $n=2$; others $n=4$ ). An elevated MIC and reduced susceptibility to metronidazole was associated with RTs 001 and $176(p=0.00$, $0.00 ; p$ adjusted $=0.03$ and 0.00 , respectively). A reduced susceptibility to vancomycin was found in two isolates (RTs 001 and 012; MIC $3 \mathrm{mg} / \mathrm{L}$ ).

Although a reduced susceptibility of the $C$. difficile isolates to metronidazole and vancomycin was rarely found, a reduced susceptibility to moxifloxacin was observed in

Table 1 Overall results from 3-months CDI surveillance in the Czech Republic; CDI Clostridium difficile infection, Cl confidential interval

\begin{tabular}{|c|c|c|}
\hline $\begin{array}{l}\text { Clostridium (Clostridioides) difficile infections (CDI) by type, } 16 \text { hospitals, } 10- \\
\text { 12/2017 }\end{array}$ & Number (\%) & Mean incidence density $(95 \% \mathrm{Cl})$ \\
\hline CDI cases & $433(100)$ & $4.5[95 \% \mathrm{Cl} 3.6-5.2]$ \\
\hline Healthcare-associated CDIs & $330(76.2)$ & $3.5[95 \%$ Cl 2.8-4.1] \\
\hline Community-associated and unknown origin CDIs & $52(12.0)$ & $0.5[95 \% \mathrm{Cl} 0.3-0.8]$ \\
\hline Recurrent CDI & $51(11.8)$ & $0.5[95 \% \mathrm{Cl} 0.3-0.7]$ \\
\hline Complicated course & $65(15.0)$ & \\
\hline Death & $88(20.3)$ & \\
\hline Characterisation of C. difficile isolates, 16 hospitals, 10-12/2017 & $379(87.5)$ & \\
\hline \multicolumn{3}{|l|}{ Ribotyping and toxin genes detection } \\
\hline Ribotype 001 & $127(33.5)$ & \\
\hline Ribotype 176 & $44(11.6)$ & \\
\hline Others (30 profiles) & $208(54.9)$ & \\
\hline Binary toxin genes positive & $75(19.8)$ & \\
\hline Antimicrobial susceptibility testing & $\begin{array}{l}\text { Susceptible } \\
(\%)\end{array}$ & Reduced susceptibility (\%) \\
\hline Metronidazole (breakpoint 2 mg/L) & $360(95.0)$ & $n=19$ (5.0), RTs: $001 n=8,027 n=6,176 n=5$ \\
\hline Vancomycin (breakpoint 2 mg/L) & $377(99.5)$ & $n=2$ (0.5), RTs: 001, $012 n=1$, each \\
\hline Moxifloxacin (breakpoint 4 mg/L) & $193(50.9)$ & $\begin{array}{l}n=186 \text { (49.1), RTs: } 001 n=114,002 n=1,012 n=8,017 \\
n=1,027 n=9, \\
033 n=1,078 n=2,126 n=3,176 n=44, \text { unrecognized } \\
n=3\end{array}$ \\
\hline
\end{tabular}


186 C. difficile isolates (49.1\%; RTs: 001, 002, 012, 017, 027, 033, 078, 126, 176, one unrecognized) and from those, 179 C. difficile isolates (96.2\%) showed Thr82Ile in the GyrA. Thirty $C$. difficile isolates susceptible to moxifloxacin used as controls were wild types.

Data on the characterisation of $C$. difficile isolates are summarized in Table 1.

\section{Clinical data analysis}

In our study, the older patients were more likely to be infected with the $C$. difficile ribotype 001 (Mean 72.7 vs 66.8 years; Median 76.0 vs 72.0 years; $p=0.00$, $\mathrm{p}$ adjusted $=$ 0.02 ) and/or with $C$. difficile strain showing a reduced susceptibility to moxifloxacin $(p=0.00$, p adjusted $=0.00)$.

All-cause mortality was associated with advanced age $(\mathrm{OR}=1.0 ; 95 \%$ CI $1.0-1.0 ; p=0.00)$, a complicated course of CDI $(\mathrm{OR}=4.2 ; 95 \%$ CI 2.4-7.4; $p=0.00)$, RT001 infection $(\mathrm{OR}=0.4 ; 95 \%$ CI $0.3-0.7 ; p=0.00)$, and/or $C$. difficile strains with a reduced susceptibility to moxifloxacin $(\mathrm{OR}=2.9 ; 95 \%$ CI $1.7-4.9 ; p=0.00)$.

The 30-days mortality was associated with advanced age $(\mathrm{OR}=1.0 ; 95 \%$ CI $1.0-1.0 ; \mathrm{p}=0.01)$, a complicated course of CDI (OR $=4.5 ; 95 \%$ CI $2.4-8.4 ; p=0.00)$, and/ or reduced susceptibility to moxifloxacin in CDI causative strains $(\mathrm{OR}=2.4 ; 95 \% \mathrm{CI} 1.3-4.3 ; p=0.00)$.

No association between age, gender, CDI origin, RT 001 or 176, binary toxin genes, a reduced moxifloxacin susceptibility, recurrent CDIs and a complicated course of CDI was found in this study.

Statistical analyses are summarised in Tables 2 and 3.

\section{Discussion}

In the Czech Republic, the CDI incidence density was shown to have a downward trend when compared to studies performed in 2014 (6.1 CDI cases per 10,000 patient-days) [15] and 2015 (5.2 CDI cases per 10,000 days) [16]. A further reduction to 3.9 cases per 10.000 patient-days was found in 2016 when the ECDC standardized protocol was adopted in 19 Czech hospitals [7]. In the currently reported surveillance period (10-12/
2017), similar mean CDI incidence density rates were observed as in the three-month period of 2016 (4.5 vs 3.9 per 10,000 patients-days) [7]. However, it is of note that although the number of hospitals participating in the current study was lower than in 2016 (16 vs 19), the number of patient-days was higher $(1,029,834$ vs 924 , 021), respectively [7].

The proportion of RTs 001 and 176, compared to other detected RTs, showed an increase of RT001 between 2014 and 2015 (24 and 33.5\%) [15, 16] and a decline in RT176 for 2014, 2015 and 2017 (29.1\%; 25.5 and $11.6 \%)[15,16]$. The proportion of RT001 in this study is the same as in 2015 (33.5\%) [16].

Importantly, the $C$. difficile isolates belonging to RTs 001 and 176 from this study were associated with elevated MICs and/or a reduced susceptibility to metronidazole ( $\mathrm{MIC} \geq 2 \mathrm{mg} / \mathrm{L}$ ). Currently, in Europe, metronidazole is recommended as a first-line CDI treatment drug for initial and non-complicated CDI [4] but, due to the growing evidence of its limited efficacy, vancomycin was suggested as a replacement for metronidazole in the CDI treatment algorithm [17]. This is in agreement with the Infectious Diseases Society of America (IDSA) and the Society for Healthcare Epidemiology of America (SHEA) guidelines [18]. In addition, two C. difficile isolates in this study showed a reduced susceptibility to vancomycin $(\mathrm{MIC}=3$ $\mathrm{mg} / \mathrm{L}$ ) yet when the patients were treated with vancomycin they improved clinically and both were discharged from hospital.

A reduced susceptibility to moxifloxacin was observed in $49.1 \%$ of the $C$. difficile isolates. Prior to this study, a high proportion of isolates that showed a reduced susceptibility to moxifloxacin was reported in European $C$. difficile isolates collected during the ClosER study, 7/ 2011-7/2014 (35.8\%) [19] and in the standardized CDI surveillance in 2016 (363/523; 69.4\% cases with data on susceptibility) [7].

The spread of fluoroquinolone-resistant $C$. difficile strains is thought to be associated with selective pressure caused by the frequent prescription of fluroquinolones

Table 2 Univariate comparison of the baseline characteristics of C. difficile infections caused by C. difficile strains of ribotype 001, ribotype 176, binary toxin genes carrying and showing the reduced susceptibility to moxifloxacin

\begin{tabular}{|c|c|c|c|c|c|c|c|c|}
\hline & \multicolumn{2}{|c|}{ Ribotype 001} & \multicolumn{2}{|c|}{ Ribotype 176} & \multicolumn{2}{|c|}{ Binary toxin genes } & \multicolumn{2}{|c|}{ Moxifloxacin (RS) } \\
\hline & $p$-value & Adjusted $p$-value & $p$-value & Adjusted $p$-value & $p$-value & Adjusted $p$-value & $p$-value & Adjusted $p$-value \\
\hline Age & 0.00 & 0.02 & 0.30 & 1.00 & 0.24 & 1.00 & 0.00 & 0.00 \\
\hline Gender & 0.16 & 0.95 & 0.02 & 0.18 & 0.03 & 0.23 & 0.39 & 1.00 \\
\hline HA CDI origin & 0.03 & 0.23 & 1.00 & 1.00 & 0.96 & 1.00 & 0.02 & 0.22 \\
\hline Recurrent CDI & 0.35 & 1.00 & 0.09 & 0.61 & 0.26 & 1.00 & 0.35 & 1.00 \\
\hline Complicated CDI & 0.27 & 1.00 & 0.12 & 0.86 & 0.90 & 1.00 & 0.93 & 1.00 \\
\hline 30-days mortality & 0.10 & 0.40 & 0.40 & 1.00 & 0.94 & 1.00 & 0.01 & 0.04 \\
\hline All-cause mortality & 0.00 & 0.01 & 0.67 & 1.00 & 0.87 & 1.00 & 0.00 & 0.00 \\
\hline
\end{tabular}

$C D I$ Clostridium difficile infection, $\mathrm{Cl}$ confidential interval, $H A$ healthcare-associated, $R S$ reduced susceptibility 
Table 3 Unadjusted analysis of selected predictors for 30-days mortality and all-cause mortality

\begin{tabular}{|c|c|c|c|c|c|c|}
\hline & \multicolumn{3}{|c|}{30 - days mortality } & \multicolumn{3}{|c|}{ All- cause mortality } \\
\hline & $\overline{\mathrm{OR}}$ & $95 \% \mathrm{Cl}$ & $\overline{p \text {-value }}$ & $\overline{\mathrm{OR}}$ & $95 \% \mathrm{Cl}$ & $p$-value \\
\hline Ribotype 001 & 0.6 & $0.3-1.1$ & 0.07 & 0.4 & $0.3-0.7$ & 0.00 \\
\hline Ribotype 176 & 0.7 & $0.3-1.4$ & 0.29 & 0.8 & $0.4-1.6$ & 0.53 \\
\hline Binary toxin genes & 1.1 & $0.5-2.2$ & 0.80 & 0.9 & $0.5-1.7$ & 0.75 \\
\hline Moxifloxacin (RS) & 2.4 & $1.3-4.3$ & 0.00 & 2.9 & $1.7-4.9$ & 0.00 \\
\hline Age & 1.0 & $1.0-1.0$ & 0.01 & 1.0 & $1.0-1.0$ & 0.00 \\
\hline Gender & 2.0 & $1.1-3.5$ & 0.02 & 1.5 & $0.9-2.4$ & 0.11 \\
\hline CDI Origin & 1.8 & $0.5-6.2$ & 0.33 & 1.6 & $0.6-4.4$ & 0.32 \\
\hline Complicated CDI & 4.5 & $2.4-8.4$ & 0.00 & 4.2 & $2.4-7.4$ & 0.00 \\
\hline
\end{tabular}

$C D I$ Clostridium difficile infection, $\mathrm{Cl}$ confidential interval, $O R$ Odds ratio, $R S$ reduced susceptibility

[5]. However, this is unlikely to be the only contributory factor. As observed by Vernon et al., fluoroquinolone resistance in C. difficile can affect bacterial fitness, in both benefit and burden, depending on the causative mutation. Thr82Ile, the most prevalent mutation in our study, exhibited a significant fitness advantage in competitive batch culture and a higher mutant-to-parent ratio in a co-culture chemostat model [20]. The fluoroquinolone resistance caused by Thr82Ile plays undoubtedly a significant role in the global spread of RT027 [21]. The impact of the Thr82Ile-mediated reduced susceptibility to fluroquinolones on the epidemiology of CDI is also supported by the detection of Thr82Ile in European C. difficile isolates with a reduced susceptibility to moxifloxacin that showed clustering within-country and are tightlyclustered geographically [22].

The hospital mortality measured in our study was at a similar level to the latest European data $(20.3 \%$ vs 20.7\%), [7]. Several studies aimed to identify the strain specific characteristics, i.e. ribotype or the presence of binary toxin genes, linked adversely to patient outcomes [23-25] and the most common ribotype found to be associated with mortality was ribotype 027 [23, 24]. Although RT176 is genetically related to the 'hypervirulent' RT027 [26], our data did not support the relationship between RT176 CDI and a poorer outcome for the patients. These data are in agreement with data on the outcome of patients infected by RTs 027 and 176 collected during the pilot European standardized CDI surveillance in 2013 [6]. Whereas in our study, RT001 CDIs were shown to be associated with all-cause mortality, this statistically significant association was not confirmed when mortality within 30-days was analysed. In addition, no association between 30-days mortality and RT001 CDI was found in the UK study, where RT001 represented $16.8 \%$ of CDI cases and $25.4 \%$ of deaths [24].

Our findings did not support the relationship between mortality and a particular ribotype, nor did we confirm the recent observation on the effect of the presence of binary toxin genes on all-cause mortality [25]. In the study of Berry et al. [25], more than a half of 213 binary toxin positive $C$. difficile isolates were RTs 027 and 078 ( $n=99$ and 65, respectively) frequently referred to as 'hypervirulent' $[23,24,27]$, whereas in our study the majority of binary toxin gene positive isolates $(n=75)$ belonged to RT176; the RTs 027 and 078 were represented by 9 and 12 isolates respectively. Similar to the study of Reigadas et al. [28], our results showed no association between the presence of binary toxin genes and recurrence or mortality in non-027 C. difficile isolates.

From the $C$. difficile strain characteristics studied here, a reduced susceptibility to moxifloxacin in $C$. difficile isolates was identified as a risk factor for all-cause mortality and 30-days mortality, therefore we believe it can be considered as a factor of pathogenicity per se. Although a reduced susceptibility to moxifloxacin is widely distributed in $C$. difficile clinical strains, the effect of this phenotype on patients' outcome has not been reported previously. In contrary to Gram-negative bacteria, fluoroquinolone resistance was found to be a risk factor for in-hospital mortality, bacteremia or sepsis caused by fluoroquinolone resistant E. coli [29, 30].

The present study has several limitations. It is a national multicentre study and thus the results can be affected by the endemic occurrence of the two ribotypes 001 and 176 in the Czech Republic. Further, data on fatal cases could have been incomplete as, in the surveillance protocol used in this study, there was no postdischarge follow-up. Further data are needed in order to evaluate the role of a reduced susceptibility to moxifloxacin in $C$. difficile strains on CDI epidemiology and the outcome of patients with CDI.

\section{Conclusion}

In our study, the amino acid substitution Thr82Ile in the GyrA was the most common molecular mechanism for a reduced susceptibility to moxifloxacin in $C$. difficile isolates. A reduced susceptibility to moxifloxacin, in causative $C$. difficile strains was associated with fatal outcome of the patients, therefore it is an important marker in surveillance of CDI.

\section{Supplementary information}

Supplementary information accompanies this paper at https://doi.org/10. 1186/s13756-020-00765-y.

Additional file 1.

Additional file 2 .

Acknowledgments

We would like to thank all members of the ESCMID study group for Clostridium difficile (ESGCD) for their active contribution to the development 
and publication of the guidance documents for CDI diagnostics, prevention and treatment.

\section{Authors' contributions}

MK, ON, PD designed study. EN, SV, MB, LG, RT, LH, IV, PC, LR, PJ, DZ, DV, AK, $\mathrm{DN}, \mathrm{MC}$ collected $C$. difficile isolates and epidemiological data at the hospital level. MK collected and analysed national epidemiological data. MK performed ribotyping and antimicrobial susceptibility testing in C. difficile isolates and wrote the first draft of the manuscript. VC performed the statistical analysis of the results. ON and PD critically revised the subsequent drafts of the manuscript. All authors approved the final version of the manuscript and agreed on its content and with its submission. The preliminary data were presented at the 29th European Congress of Clinical Microbiology \& Infectious Diseases in Amsterdam, the Netherlands.

\section{Funding}

The characterisation of $C$. difficile isolates was supported by MH CZ - DRO, University Hospital Motol, Prague, Czech Republic 00064203.

\section{Ethics approval and consent to participate}

For this type of study formal consent was not required.

\section{Competing interests}

The authors declare that they have no conflicts of interest.

\section{Author details}

'Department of Medical Microbiology, Charles University, 2nd Faculty of Medicine and Motol University Hospital, Prague, Czech Republic. ${ }^{2}$ Bioinformatics centre, 2nd Faculty of Medicine, Charles University, Prague, Czech Republic. ${ }^{3}$ Department of Medical Microbiology, Hospital Bulovka, Prague, Czech Republic. ${ }^{4}$ Department of Medical Microbiology, University Hospital Brno, Brno, Czech Republic. ${ }^{5}$ Department of Medical Microbiology, Hospital Ceske Budejovice, Ceske Budejovice, Czech Republic. ${ }^{6}$ Department of Medical Microbiology, Faculty of Medicine, Charles University and University Hospital Plzen, Plzen, Czech Republic. ${ }^{7}$ Department of Medical Microbiology, Faculty of Medicine, Masaryk University and St. Anne's University Hospital, Brno, Czech Republic. ${ }^{8}$ Department of Medical Microbiology and Immunology, Hospital Liberec, Liberec, Czech Republic. ${ }^{9}$ Department of Microbiology, Faculty of Medicine and Dentistry, Palacky University Hospital, Olomouc, Czech Republic. ${ }^{10}$ Department of Medical Microbiology, Thomayer's Hospital, Prague, Czech Republic. ${ }^{11}$ Department of Clinical Microbiology, University Hospital Hradec Kralove, Hradec Kralove, Czech Republic. ${ }^{12}$ Department of Clinical Microbiology and Parasitology, Hospital Pribram, Pribram, Czech Republic. ${ }^{13}$ Department of Clinical Microbiology, Hospital Nove Mesto na Morave, Nove Mesto na Morave, Czech Republic. ${ }^{14}$ Department of Medical Microbiology, Hospital Jindrichuv Hradec, Jindrichuv Hradec, Czech Republic. ${ }^{15}$ Department of Medical Microbiology, Hospital Tabor, Tabor, Czech Republic. ${ }^{16}$ Department of Clinical Microbiology, Institute for Clinical and Experimental Medicine, Prague, Czech Republic. ${ }^{17}$ Department of Clinical Microbiology, Military University Hospital, Prague, Czech Republic.

Received: 27 March 2020 Accepted: 23 June 2020 Published online: 30 June 2020

\section{References}

1. Oren A, Rupnik M. Clostridium difficile and Clostridioides difficile: two validly published and correct names. Anaerobe. 2018;52:125-6. https://doi.org/10. 1016/j.anaerobe.2018.07.005.

2. European Centre for Disease Prevention and Control. Point prevalence survey of healthcare-associated infections and antimicrobial use in European acute care hospitals. Stockholm: ECDC; 2013.

3. Krutova M, Kinross P, Barbut F, Hajdu A, Wilcox MH, Kuijper EJ, Survey contributors. How to: surveillance of Clostridium difficile infections. Clin Microbiol Infect. 2018;24(5):469-75. https://doi.org/10.1016/j.cmi.2017.12. 008.

4. Debast SB, Bauer MP, Kuijper EJ, European Society of Clinical Microbiology and Infectious Diseases. European Society of Clinical Microbiology and Infectious Diseases: update of the treatment guidance document for Clostridium difficile infection. Clin Microbiol Infect. 2014;20(Suppl 2):1-26. https://doi.org/10.1111/1469-0691.12418.
5. Dingle KE, Didelot X, Quan TP, Eyre DW, Stoesser N, Golubchik T, et al. Effects of control interventions on Clostridium difficile infection in England: an observational study. Lancet Infect Dis. 2017;17(4):411-21. https://doi. org/10.1016/S1473-3099(16)30514-X.

6. van Dorp SM, Kinross P, Gastmeier P, Behnke M, Kola A, Delmée M, et al. Standardised surveillance of Clostridium difficile infection in European acute care hospitals: a pilot study, 2013. Euro Surveill. 2016;21(29). https://doi. org/10.2807/1560-7917.ES.2016.21.29.30293.

7. European Centre for Disease Prevention and Control. Clostridium difficile infections. In: ECDC. Annual epidemiological report for 2016. Stockholm: ECDC; 2018

8. European Centre for Disease Prevention and Control. European Surveillance of Clostridium difficile infections. Surveillance protocol version 2.3 Stockholm: ECDC; 2017.

9. Institute of health information and statistics of the Czech Republic (UZIS). Inpatient care. Prague: UZIS. Czech. Available from: https://www.uzis.cz/ publikace/luzkovy-fond-2017. [Accessed 19 Sept 2019].

10. Crobach MJ, Planche T, Eckert C, Barbut F, Terveer EM, Dekkers OM, et al. European Society of Clinical Microbiology and Infectious Diseases: update of the diagnostic guidance document for Clostridium difficile infection. Clin Microbiol Infect. 2016;22(Suppl 4):S63-81. https://doi.org/10.1016/j.cmi.2016. 03.010 .

11. Fawley WN, Knetsch CW, MacCannell DR, Harmanus C, Du T, Mulvey MR, et al. Development and validation of an internationally-standardized, highresolution capillary gel-based electrophoresis PCR-ribotyping protocol for Clostridium difficile. PLoS One. 2015;10(2):e0118150. https://doi.org/10.1371/ journal.pone.0118150.

12. Persson $\mathrm{S}$, Torpdahl M, Olsen KE. New multiplex PCR method for the detection of Clostridium difficile toxin $A(t c d A)$ and toxin $B(t c d B)$ and the binary toxin $(c d t A / c d t B)$ genes applied to a Danish strain collection. Clin Microbiol Infect. 2008;14(11):1057-64. https://doi.org/10.1111/j.1469-0691. 2008.02092.x Erratum in: Clin Microbiol Infect. 2009;15(3):296.

13. Dridi L, Tankovic J, Burghoffer B, Barbut F, Petit JC. gyrA and gyrB mutations are implicated in cross-resistance to ciprofloxacin and moxifloxacin in Clostridium difficile. Antimicrob Agents Chemother. 2002;46(11):3418-21.

14. Core Team R. R: a language and environment for statistical computing. Vienna: R Foundation for Statistical Computing; 2018. https://www.Rproject.org.

15. Krutova M, Matejkova J, Kuijper EJ, Drevinek P, Nyc O. Czech Clostridium difficile study group. Clostridium difficile PCR ribotypes 001 and 176 - the common denominator of $C$. difficile infection epidemiology in the Czech Republic, 2014. Euro Surveill. 2016;21(29). https://doi.org/10.2807/1560-7917. ES.2016.21.29.30296

16. Krutova M, Matejkova J, Drevinek P, Kuijper EJ, Nyc O, study group. Increasing incidence of Clostridium difficile ribotype 001 associated with severe course of the infection and previous fluoroquinolone use in the Czech Republic, 2015. Eur J Clin Microbiol Infect Dis. 2017;36(11):2251-8. https://doi.org/10.1007/s10096-017-3055-Z.

17. Ooijevaar RE, van Beurden YH, Terveer EM, Goorhuis A, Bauer MP, Keller Jر J Mulder CJJ, Kuijper EJ. Update of treatment algorithms for Clostridium difficile infection. Clin Microbiol Infect. 2018:24(5):452-62. https://doi.org/10. 1016/j.cmi.2017.12.022.

18. McDonald LC, Gerding DN, Johnson S, Bakken JS, Carroll KC, Coffin SE, Dubberke ER, Garey KW, Gould CV, Kelly C, Loo V, Shaklee Sammons J, Sandora TJ, Wilcox MH. Clinical practice guidelines for Clostridium difficile infection in adults and children: 2017 update by the Infectious Diseases Society of America (IDSA) and Society for Healthcare Epidemiology of America (SHEA). Clin Infect Dis. 2018;66(7):987-94. https://doi.org/10.1093/ cid/ciy149.

19. Freeman J, Vernon J, Pilling S, Morris K, Nicholson S, Shearman S, et al. The ClosER study: results from a three-year pan-European longitudinal surveillance of antibiotic resistance among prevalent Clostridium difficile ribotypes, 2011-2014. Clin Microbiol Infect. 2018;24(7):724-31. https://doi. org/10.1016/j.cmi.2017.10.008.

20. Vernon JJ, Wilcox MH, Freeman J. Effect of fluoroquinolone resistance mutation Thr-82 $\rightarrow$ Ile on Clostridioides difficile fitness. J Antimicrob Chemother. 2019;74(4):877-84. https://doi.org/10.1093/jac/dky535.

21. He M, Miyajima F, Roberts P, Ellison L, Pickard DJ, Martin MJ, Connor TR, Harris SR, Fairley D, Bamford KB, D'Arc S, Brazier J, Brown D, Coia JE, Douce G, Gerding D, Kim HJ, Koh TH, Kato H, Senoh M, Louie T, Michell S, Butt E, Peacock SJ, Brown NM, Riley T, Songer G, Wilcox M, Pirmohamed M, Kuijper 
E, Hawkey P, Wren BW, Dougan G, Parkhill J, Lawley TD. Emergence and global spread of epidemic healthcare-associated Clostridium difficile. Nat Genet. 2013;45(1):109-13. https://doi.org/10.1038/ng.2478.

22. Eyre DW, Davies KA, Davis G, Fawley WN, Dingle KE, De Maio N, Karas A, Crook DW, Peto TEA, Walker AS, Wilcox MH, EUCLID Study Group. Two distinct patterns of Clostridium difficile diversity across Europe indicating contrasting routes of spread. Clin Infect Dis. 2018;67(7):1035-44. https://doi. org/10.1093/cid/ciy252.

23. Rao K, Micic D, Natarajan M, Winters S, Kiel MJ, Walk ST, Santhosh K, Mogle JA, Galecki AT, LeBar W, Higgins PD, Young VB, Aronoff DM. Clostridium difficile ribotype 027 : relationship to age, detectability of toxins A or B in stool with rapid testing, severe infection, and mortality. Clin Infect Dis. 2015; 61(2):233-41. https://doi.org/10.1093/cid/civ254.

24. Inns T, Gorton R, Berrington A, Sails A, Lamagni T, Collins J, Perry J, Hill K, Magee J, Gould K. Effect of ribotype on all-cause mortality following Clostridium difficile infection. J Hosp Infect. 2013;84(3):235-41. https://doi. org/10.1016/j.jhin.2013.04.008.

25. Berry CE, Davies KA, Owens DW, Wilcox MH. Is there a relationship between the presence of the binary toxin genes in Clostridium difficile strains and the severity of C. difficile infection (CDI)? Eur J Clin Microbiol Infect Dis. 2017; 36(12):2405-15. https://doi.org/10.1007/s10096-017-3075-8.

26. Krutova M, Matejkova J, Nyc O. C. difficile ribotype 027 or 176 ? Folia Microbiol. 2014;59(6):523-6. https://doi.org/10.1007/s12223-014-0323-5.

27. Walker AS, Eyre DW, Wyllie DH, Dingle KE, Griffiths D, Shine B, Oakley S, O'Connor L, Finney J, Vaughan A, Crook DW, Wilcox MH, Peto TE. Infections in Oxfordshire research database. Relationship between bacterial strain type, host biomarkers, and mortality in Clostridium difficile infection. Clin Infect Dis. 2013;56(11):1589-600. https://doi.org/10.1093/cid/cit127.

28. Reigadas E, Alcalá L, Marín M, Martín A, Iglesias C, Bouza E. Role of binary toxin in the outcome of Clostridium difficile infection in a non-027 ribotype setting. Epidemiol Infect. 2016;144(2):268-73. https://doi.org/10.1017/ S095026881500148X Erratum in: Epidemiol Infect. 2016;144(12):2691.

29. Camins BC, Marschall J, DeVader SR, Maker DE, Hoffman MW, Fraser VJ. The clinical impact of fluoroquinolone resistance in patients with $E$ coli bacteremia. J Hosp Med. 2011;6(6):344-9. https://doi.org/10.1002/jhm.877.

30. Goldstein E, MacFadden DR, Karaca Z, Steiner CA, Viboud C, Lipsitch M. Antimicrobial resistance prevalence, rates of hospitalization with septicemia and rates of mortality with sepsis in adults in different US states. Int J Antimicrob Agents. 2019;54(1):23-34. https://doi.org/10.1016/j.jantimicag. 2019.03.004.

\section{Publisher's Note}

Springer Nature remains neutral with regard to jurisdictional claims in published maps and institutional affiliations.

Ready to submit your research? Choose BMC and benefit from:

- fast, convenient online submission

- thorough peer review by experienced researchers in your field

- rapid publication on acceptance

- support for research data, including large and complex data types

- gold Open Access which fosters wider collaboration and increased citations

- maximum visibility for your research: over $100 \mathrm{M}$ website views per year

At $\mathrm{BMC}$, research is always in progress.

Learn more biomedcentral.com/submissions 